\title{
Retention and Retrieval of Unidirectional, Paired-associate Verbal Input
}

\author{
Mehmet OZCAN ${ }^{1}$ \\ ${ }^{1}$ Mehmet Akif Ersoy University, Turkey \\ Correspondence: Mehmet OZCAN, Mehmet Akif Ersoy University, Turkey. E-mail: mozcan@mehmetakif.edu.tr
}

Received: August 6, 2012 Accepted: September 4, 2012 Online Published: September 6, 2012

doi:10.5539/elt.v5n11p29 URL: http://dx.doi.org/10.5539/elt.v5n11p29

\begin{abstract}
This study is designed to investigate whether the sequence of input is influential in the recollection of the retained information. Eighty first year students, 40 girls and 40 boys, studying in ELT department participated in the study. Three tasks were administered to the participants. In the first test three different lists of words and their counterparts are given. The participants were asked to learn the words in a column and their counterparts in the next one. They were informed that they were going to be given a test two days later. In the second test, administered two days later following the first one, they were given the lists as the sequence of the words was reversed. In the third test, the participants were given the words tea, window, spill and break as a free association test. While the failure in the recollection of paired-associate words in Forward Recall tests was low, it was significantly high in Backward Recollection tests. The findings show that the sequence of the input at the time of retention is crucial in the recollection of the information stored in memory.
\end{abstract}

Keywords: retention, recollection, unidirectional input, forward recollection, backward recollection, vocabulary teaching

\section{Introduction}

Factors affecting the retention of verbal input vary depending on the learner (Busato, Prins, Elshout and Hamaker (1999); Gagnon, Bedard and Turcotte, 2005; Matthews, 2009: 400; Phillips, 1988; Postma, Jager, Kessels, Koppeschaar and van Honk, 2004), context (Byers, 1967; Prince, 1996; Tessmer and Richey, 1997), method (Mc Donald, 1964) and nature of input (Kerzel, 2003) along with other minor ones. The retention of input and the factors related to learner, context, method and nature of the input are in interplay to the extent all of the factors that are present in a specific learning environment allow one factor to be predominating over the others. Thus, it is difficult to assign an absolute importance to one of them without having a certain learning environment whose features are defined clearly (see Ausubel and Fitzgerald, 1961; Craik and Tulving, 1975).

\subsection{Learner vis-à-vis Verbal Input}

Learner differences in the retention and retrieval of input stem mostly from aptitudinal and attitudinal factors. Aptitudinal factors can be detailed as neuroanatomic functioning of brain, cognition, learning styles, personal experiences and the organization of episodic memories in the brain and mind of a learner. Habib, McIntosh and Tulving (2000) examined individual differences in the neuroanatomical correlates of multi-trial verbal discrimination learning in 16 young healthy subjects. They identified that patterns of brain regions in which blood flow correlated with subjects' retrieval performance. They interpreted their findings stating that individual differences in memory performance are related to differences in neural activity within specific brain circuits. As Piaget demonstrated it in volumes of books, cognitive potential of a learner is crucial in the retention and retrieval of input. While perceiving and producing an instant response to the perceived item require lower order cognitive skills such as matching or recognition, conceptualization of this input requires deeper processing in mind (See Budvig, 2002: 59-60). For example children at younger age cannot conceive of Newtonian time in the way adults do. So while weeks, months and years mean something in adults' mind, most of the children younger than 5 years of age live in "today" which is the blurred extension of deictic now, which is the only real time for them. Learning styles are "characteristic cognitive, affective, and psychological behaviors that serve as relatively stable indicators of how learners perceive, interact with, and respond to the learning environment" (Felder and Brent, 2005). Attitudinal factors, on the other hand, are more related to environmental factors which inspire a learner how to react towards learning. These factors can be social, economic, pragmatic and cultural. 


\subsection{Context vis-à-vis Verbal Input}

Context constructs a framework for input, where learner can conceptualize input in the way it functions in a specific environment. A child begins to wave good bye not when people come home but while they are leaving because this hypothetical child acquires the act of waving with all other surrounding conditions (see Fernandez and Cairns, 2010: 7-9, 43). Dijkstra, Kaschak and Zwaan (2007) assessed the potential facilitation of congruent body posture on access to and retention of autobiographical memories in younger and older adults. They found that "the response times were shorter when body positions during prompted retrieval of autobiographical events were similar to the body positions in the original events than when body position was incongruent". Their findings imply that when human mind processes input to store it in long term memory, it processes it with all surrounding relevant entities with their most foregrounded features at the stage of perception and registration. In any learning process, mind performs associative and then dissociative tasks. When an organism perceives new input, it seeks the ways to relate it to already existing elements in the schemata in mind. This stage is called association. In this dynamic process, new input is associated with the schema which possesses more features to assimilate the new input compared to other schemata. After the association, new input must be dissociated from each of the element to some degree so that the new input can gain its own identity and so that it can be contributive to the schema to which it is related. In other words, this process is the interaction between conflicting constraints in the way Prince and Smolensky (1993) propose it in Optimality Theory. In the perception and retention of input, the number of other surrounding entities that are likely to compete with the input to be retained must have an impact on the quality and strength of the dissociation of this new input from already assimilated input in the mind. However, when the input is perceived among non-similar entities, it is easier to retain it since it would be foregrounded in the micro environment where the input is located, though the defining features of the input retained in this way would not be as subtle as those of the input retained in the former case (see Maki, 2007; Özcan, 2012a). Within language learning or acquisition, vocabulary learning is a crucial part. It is often observed that one technique practiced in classes to teach vocabulary is listing unknown words on the board with their translations in L1 placed in an adjacent column (see Baleghizadeh and Ashoori, 2010). Word lists which contain unknown words to the learner require strong dissociative abilities because listed words present so many conflicting constraints regarding their content, orthographic and phonological form and category. Thus processing such word lists and the context where the input is received become a factor in the retention of input.

Smith (1979) tested learners in and out of the contexts where input is processed. He found that retrieval process is more successful if the learners are tested in the context of input processing. He also reports that learners can supply their own contextual clues when the context can be easily recalled. This implies that mental activation of context influences the retrieval of knowledge which is processed in that specific context (see also Thomson and Tulving 1970; Davies and Milne, 1982).

\subsection{Method vis-à-vis Verbal Input}

Among other factors which affect the retention of input, the way the input is perceived and assimilated plays a crucial role. Ausubel and Fitzgerald (1961) carried out a study to investigate how advance organizers would contribute to learning of a text. They found that when the learners are presented with advance organizers before they settle down to read a larger text, the presentation of the organizers foster the learning by preparing the learner for the larger text. Mnemonic method has been used since ancient times in the memorizations of specific parts of a play relating those parts to some certain objects which the actors or actresses would be facing in the theatre building during the performance of the play. Atkinson and Raugh (1975) used mnemonic technique to teach vocabulary. The experiment they carried out compared the keyword method with an unconstrained control procedure using Russian vocabulary. They report that on all measures the keyword method proved to be highly effective, yielding for the most critical test a score of $72 \%$ correct for the keyword group compared to $46 \%$ for the control group. Wyra, Lawson and Hungi (2007) investigated the influence of mnemonic keyword method in vocabulary learning. They found that when a word is associated with some image or with a phonological form which is already known by the learner, that word is recalled easier in recall tests compared to the recall of words learned through standard keyword method. Craik and Tulving (1975) conducted a series of experiments to test the relationship between the depth of processing and retention of the input, where, as they explain, "depth" refers to greater degrees of semantic involvement. In their study they presented some words to the participants and then posed some questions about each word. They found that retention depends critically on the qualitative nature of the encoding operations performed; a minimal semantic analysis is more beneficial than an extensive structural analysis. 


\subsection{The Nature of Verbal Input}

Nature of input has an effect on its retention by learners. Input is encountered by learners in the forms of object, image, symbol and concept. While an object (e.g. a sheep) as a new input presents many perceptual features to learners, the image (picture of a sheep) of the same object is devoid of some of those features. For instance the picture of a sheep does not present the same perceptual features; it is not as soft as the wool of the sheep, it does not move, it does not smell. The form of the input sheep in symbolic order is its arbitrary linguistic representative, viz, phonologically / i p/and orthographically sheep. These symbols are totally arbitrary in the sense that there is no relation between the form of the word sheep and the object itself. The only relationship is conceptual. The word sheep is the trigger of the schema of the concept of sheepness. Even one single object presents at least four different forms of input which range from being concrete to abstract. It cannot be assumed that the retention of each form would require the same mental processes. Schulman (1974) investigated the influence of congruity of the qualities of entities in the questions posed to learners on the retention of the words which refer to those entities. His findings show that "words from "incongruous" queries (e.g. Is a chapter slippery?) almost invariably were more poorly remembered under conditions of free recall, cued recall, and recognition memory than words from "congruous" queries (e.g. Is a bubble a sphere?). The study argues that "the large and pervasive memorial advantages of congruity arise because a congruous query, unlike an incongruous one, fosters a relational encoding of keyword (bubble) and descriptor (sphere)."

Recent vocabulary learning research has been based on cognitive interactionist theories of psycholinguistics and second language acquisition (SLA), which emphasize the importance of input, interaction and output in the SLA process (Sankó, 2006). We believe that vocabulary teaching/learning is one of the most important parts of language learning and we believe that if vocabulary is not presented to learners in the way mind can retain and then recollect it, the productive skills of learners will be poorer than the learning or teaching objectives presuppose it (see Gass, 2003:225-227).

From among these factors, the least studied is the relationship between retention and sequential positioning of verbal input at the time of learning (see Richardson and Hersh, 1974). This experimental study in your hand is designed to delve into the relationship between sequential positioning of verbal input and its retention.

\section{Method}

\subsection{Participants}

Participants are 80 first year students, 40 girls and 40 boys, studying in ELT departments. The participants were recruited randomly from among the students of ELT departments. They were divided into four groups to perform the task the study required.

\subsection{Data Collection}

Data were collected using paired word lists to be learned and to be recollected in the forms of forward and backward recollection by the participants in three different tasks. In order to clarify the concepts of Forward and Backward Recollection, a brief definition is needed. Forward Recollection refers to the recollection of two associated elements in the way the organism processes them during the retention. For instance, if two items paired in the form of A-B are learned and then A is given to the learner to stimulate B in a test, such recollection is called forward recollection. Backward Recollection refers to the recollection of two associated elements in the reverse order the organism processes them during the retention. If two items paired in the form of A-B are learned and then $\mathrm{B}$ is given to the learner as the stimulant in a test, such recollection is called backward recollection.

\subsubsection{Task 1: Forward Recollection (FR) Test}

In the first task, 20 participants (Group 1), 10 boys and 10 girls, were given a list of twenty English Words in a column and their Synonyms in the next. They were asked to study the words (henceforward WORD) and their synonyms (henceforward SYN). The participants were informed that they were going to be tested two days later. Two days later, they were given a list which contained only WORDs and they were asked to write down the SYNs for each WORD. This task was given to test how the learners' mind work in the retention and recollection of paired verbal items within target language.

The second group of 20 participants (Group 2), 10 girls and 10 boys, were given the list of twenty English words in a column and their Turkish counterparts in the next one. They were asked to learn the English words and their Turkish counterparts. The participants were informed that they were going to be tested two days later. Two days later, they were given the list of the English words they had studied and were asked to write down the Turkish counterparts. This task was given to test how learners' mind work in retention and recollection of paired verbal 
items when one of the items is known and the other one is not known within a known language (English) to the learner.

The third group of 20 participants (Group 3), 10 girls and 10 boys, were given a list of twenty French words in a column and their Turkish counterparts in the next one. None of the participants knew French. They were asked to learn the French words and their Turkish counterparts. They were informed that they were going to be tested two days later. Two days later, they were given the list of French words and were asked to write down their Turkish counterparts. This task was given to understand how learners' mind work in the retention and recollection of paired verbal items when one of the item is known but the other one is unknown within an unknown language (French).

\subsubsection{Task 2: Backward Recollection (BR) Test}

The following day, the participants in Group 1 were given the list of the SYNs and they were asked to write down the WORDs they had learned; the participants in Group 2 were given the list of Turkish words and were asked to write down the English counterparts of those words which they had learned; the participants in Group 3 were given the list of the Turkish words and were asked to write down their French counterparts which they had learned. None of the participants were informed that they were going to be tested again and all the tests were given to all three groups simultaneously.

\subsubsection{Task 3: Free Association Test}

This test has been administered, to 20 participants (Group 4) (10 boys and 10 girls) in order to obtain data on the question whether people have a common schema related to certain words that are followed by certain other words and whether this schema is helpful in backward recollection. The participants were presented with the words 'spill' and 'break'. They were asked to write down the words which the two given words remind them. Two days later the same 20 participants were given the words 'tea' and 'window', without being informed beforehand, as stimuli and they were asked to write down the words which these two words remind them. All of the participants produced a response.

\subsection{Data Analysis}

Data were analyzed with a more quantitative perspective because our concern is with the amount of input that is retained in long term memory and its retrieval by FR and BR. However, we dealt with the quality of some parts of the data to support our quantitative findings. To obtain the desired proportional values, the number of the participants who failed to retrieve in FR or BR in each group for each word is identified and then mean numbers and proportions were calculated.

\section{Findings}

\subsection{Task 1}

Task 1requires the participants to recall the input in the same way they studied it (FR). It is observed that all of the three groups scored very high in the recollection of the items in each task. Group 1, whose task was to recall the SYNs for the WORDs failed to recall $2.25 \%$ of the SYNs correctly. The failure $(2.25 \%)$ was related to some certain words rather than applying to all of the words on the list. The failure in this task was with only three SYNs; $15 \%$ of the participants failed to recall one of the SYNs, where $\mathrm{m}=0.45, \mathrm{n}=9, \mathrm{Sd}=1.27$. Group 2, whose task was to recall the Turkish counterparts of English words, failed to recall $2.25 \%$ of the input. The failure in this task is also with three words; $15 \%$ of the participants failed to recall one Turkish counterpart of English word, $5 \%$ with one word and $35 \%$ with another, where $\mathrm{m}=0.55, \mathrm{n}=11$ and $\mathrm{Sd}=1.66$. Seventeen Turkish counterparts were recalled correctly by all of the participants.

Group 3, whose task was to recall the Turkish counterparts of French words, failed to recall $0.75 \%$ of Turkish counterparts of French words. The failure in this task was with two words; $5 \%$ of the participants failed to recall one Turkish counterpart and $10 \%$ of them failed to recall another one, where $\mathrm{m}=0.15, \mathrm{n}=3$ and $\mathrm{Sd}=0.48$. Eighteen of the Turkish counterparts of French words were recalled correctly.

\subsection{Task 2}

Task 2 requires the participants to recall the input in the reverse order of the sequence they studied it (BR). The participants Group 1were asked to write down the SYNs for the WORDs. They failed to recall $21.75 \%$ of the WORDs, which is $2.25 \%$ in FR tests. The proportion of individual words the participants failed to recall ranges from $0 \%$ to $65 \%$; where $\mathrm{m}=4.35, \mathrm{n}=87, \mathrm{Sd}=3.96$. For instance, while no participants failed to recollect the word bewildered, 13 participants failed to recollect the word disordered in BR tests. We checked the data to find out a correlation between the length of the words provided and the achievement in recollection but there was no 
relationship between them.

The participants in Group 2, whose task was to recall the English words as BR, failed to recall $14.5 \%$ of the words on the list, which is $2.25 \%$ in FR tests. The participants' failure in this task is with 11 words, where $\mathrm{m}=2.9$, $\mathrm{n}=58, \mathrm{Sd}=3.33$.

The participants in Group 3, whose task was to recall French words as BR, failed to recall $16.25 \%$ of the French words, which is $0.75 \%$ in FR tests. The failure was with 11 French words in this BR task, where $\mathrm{m}=1.6, \mathrm{n}=25$ and $\mathrm{Sd}=1.81$.

Table 1. Failure in Forward Recall (FR) and Backward Recall (BR) tests

\begin{tabular}{llll}
\hline & Group 1 (\%) & Group 2 (\%) & Group 3 (\%) \\
\hline Task 1 (FR) & 2,25 & 2,25 & 0,75 \\
\hline Task 2 (BR) & 21,75 & 14,50 & 16,25 \\
\hline
\end{tabular}

\subsection{Task 3}

The words they wrote down for each stimulant and the frequency of the emergence of each associate are given in Table 2. The word tea stimulated the co-occurring words break, glass, cup and spoon. The words that are likely to co-occur with the word window in Table 2 are curtain, scene, glass and dust. However, it is questionable whether the pairs such as "window curtain", window scene", window glass" and "window dust" are collocations or not. Under the word spill, the words that refer to the entities which are likely to be "spilled" emerged as the ones which go together with the word spill very often. These words are water, milk, tea, sweat, liquid, coffee and soup. The word "sweat" is included as a result of conceptual interference of Turkish with English. Turkish has a collocative structure such as "Ter dökmek" (verbatim: "sweat spill*"). The word break stimulated co-occurring words heart, window, leg, time, school, glass, vase, pencil and dance.

Along with collocations in the form of "tea ...", "window ...", "spill ..." and "heart ...", other words which do not co-occur but complete mental schema emerged in the free association tests.

Table 2. Words given (tea, window, spill and break), their associates and frequencies

\begin{tabular}{|c|c|c|c|c|c|c|c|}
\hline tea & Freq. & window & Freq. & spill & Freq. & break & Freq. \\
\hline break* & 1 & air & 1 & magic & 4 & heart* & 3 \\
\hline breakfast & 3 & cold & 1 & mystery & 1 & window* & 2 \\
\hline cigarette & 1 & curtail & 2 & charm & 1 & leg* & 3 \\
\hline glass* & 2 & curtain* & 2 & witch & 1 & time* & 2 \\
\hline hot & 2 & fresh air & 1 & cartoon & 1 & school* & 1 \\
\hline my mum & 1 & fresh weather & 1 & water* & 5 & work & 1 \\
\hline relax & 2 & sky & 3 & milk* & 1 & glass* & 2 \\
\hline sugar & 7 & snow & 1 & slowly & 3 & stick & 1 \\
\hline cup* & 5 & sun & 1 & tea* & 1 & loudly & 1 \\
\hline canteen & 1 & view & 2 & sweat* & 1 & holiday & 1 \\
\hline I am & 1 & scene* & 1 & power & 1 & relax & 1 \\
\hline my father & 1 & my room & 1 & imagination & 1 & lesson & 1 \\
\hline spoon* & 1 & moon & 1 & liquid* & 1 & car & 2 \\
\hline \multirow[t]{9}{*}{ pleasure } & 1 & house & 1 & wet & 1 & interval & 1 \\
\hline & & door & 1 & coffee* & 1 & vase* & 1 \\
\hline & & rain & 1 & magnificent & 1 & pencil* & 1 \\
\hline & & street & 1 & to spill over & 1 & rest & 1 \\
\hline & & hot & 1 & child & 1 & stop & 1 \\
\hline & & glass* & 1 & dirty & 1 & give up & 1 \\
\hline & & dust* & 1 & soup* & 1 & dance* & 1 \\
\hline & & & & burn & 1 & dormitory & 1 \\
\hline & & & & & & eating & 1 \\
\hline
\end{tabular}


Although gender is not under the focus of this study, we observed no gender differences in FR, BR and free association test results.

\section{Discussion and Conclusion}

The comparative analysis of the findings obtained from Task 1 and Task 2 implies that the recollection of input is closely related with the positional and sequential organization of input. While the participants were able to recollect almost all of the input in FR tests, the amount of the recollection in BR tests decreases significantly. The findings obtained from Group 3 in Task 1 are interesting in that the learners achieved higher scores in the recollection of the French words although none of them knew French. This high score may have stemmed from the unassociated nature of French words. The participants are native speakers of Turkish and they are learners of English. When they encounter a new English word, they may mistake this new word for a word they learned before because of the similarities between the new word and known one. Sometimes the features of Turkish counterpart of the known word may interfere with the learning process of the new word. For instance, as English teachers we often hear students uttering an unrelated word in the place of a word (see Özcan, 2012b). One of my students translated the word reason into Turkish as mevsim, which actually means season. This is because there are strong phonologic and orthographic similarities between the two words. French words given to Group 3 in Task 1 are not related to any previously learned words. Thus, the clarity of the French words may have increased the scores in this task.

The findings obtained from Task 1 and Task 2 are significant for vocabulary teaching in foreign language (FL) classes. In vocabulary teaching, teachers' assigning students to memorize some word lists (Niu and Andrews, 2012), usually in the form of "target language words - native language counterpart", is not uncommon. When vocabulary is taught in the form of the lists in the way we designed the tests in this study, our findings imply that learners will not be able to achieve BR. This fail in recollection will result in poor production because foreign language learners make use of their first language in the production of the target language especially if the proficiency in the target language is low (Ringbom, 1987: 39).

The influence of the sequential order is further discussed referring to two personal experiences:

First

A family eats fruit at the time of news on TV after dinner and usually, it is the father who takes the tray full of fruit from the kitchen to the living room. One day, after lunch this time, he was taking the same tray to the living room. When he was leaving the kitchen with the tray in his hand, he attempted to turn off the light of the kitchen although the light was not on because it was daytime. Until that time, he had never noticed that he had been turning off the light whenever he was leaving the kitchen with a fruit tray in his hand. Another thing he had noticed was that he had never attempted to turn off the light without that tray in his hand although he had entered and left the kitchen for many times at day time.

Second

The dinner table was ready. Children were running around the table. The father warned them in English. 'Be careful! You'll spill the tea' although there was no tea on the table but, instead, there was soup.

Along with your own personal experiences, like the ones above, you might have heard many others from the people around you. How can that person's attempt to turn off the light when there was a fruit tray in his hand but not to attempt to do it when that tray did not exist and his uttering the word 'tea' instead of 'soup' right after the word 'spill' be explained?

There are, mainly, two approaches which explain the reason for such behavior. One of them is behaviorist approach, which provides an explanation as 'learning is a process of changing behavior through the use of external reinforcement to train learners to give conditioned responses to selected stimuli' (Chastain, 1988, 87). The second one is cognitive approach, which explains learning as 'a meaningful process of relating new events or items to already existing cognitive concepts or propositions- hanging new items on existing cognitive pegs (Brown, 1994, 79).

According to behaviorists, these two events are typical classical conditioning; the concept which was developed by Russian psychologist Pavlov. His well-known studies have shown that when an organism is conditioned to a certain stimulus, it responds it automatically in the same way it is conditioned whenever it receives that stimulus. With the habitualization of the response, it turns out to be learned behavior. In the light shed by this explanation, the person's attempt to turn off the light at daytime when the light had already been off is explained as, "it occurred as a response to the stimulus of holding a tray in his hand.' In the same way, he uttered the word 'tea' instead of uttering the word 'soup' since that person was conditioned to response to the stimulus 'spill' with the 
word 'tea' rather than the word "soup". Such a conditioning occurred because tea is spilled oftener than soup in that person's life (Turkish people drink tea in small bottomed thin glasses (not cups), so it is more prone to be spilled than soup which is usually eaten in larger bottomed special bowls).

On the other hand, cognitivists oppose behaviorists' hypothesis by postulating that learning cannot be accounted for by such a simple stimulus- response (S-R) relationship. They explain the events narrated above as, 'the person attempted to turn off the light in order to complete the missing part of the schema in his mind. He created a schema through his experience. This schema has been consisted of the components of taking the tray in his hand, turning off the light and leaving the kitchen. According to cognitivists, the person completed the schema by attempting to turn the light off although it had already been off. That person's uttering the word 'tea' instead of 'soup' can be accounted for by the same reason. The schema of spilling in the person's mind contains the component of 'tea' rather than 'soup'; thus, he completes that schema with the word 'tea'. Regarding the findings of Task 3, the transitive verb 'spill' caused the emergence of the words such as 'tea, milk, water, soup'; and the transitive verb 'break' stimulated the participants to write down words such as 'window, glass, heart, rules' as collocations. Thus, the two words, 'spill' and 'break', are stimulants for the words that are likely to be 'spilled' or 'broken'. The words 'tea' and 'window' did not play a role as stimulants for the words 'spill' and 'break'. This implies that learning these two pairs in a serial relation as, 'spill the water' and 'break the window' has an effect on the recollection of each word independently.

If it were only the schemata that spur the activation of certain components in relation without any serial or parallel order, (in other words if it were not the way of the storage of the input in the memory which affects the recall of that input) the words 'spill' and 'break' would take place in the association lists of the subjects who were presented with the words 'tea' and 'window'. They would be activated as a completing component of the incomplete schemata.

There are also pieces of evidence which support what cognitivists hypothesize. The emergence of the words such as "breakfast, cigarette, my mum etc." after the word tea; "liquid, child, dirty etc." after the word spill; "holiday, relax, interval, stop etc." after the word break in free association tasks implies that "completion of mental schemata" is also operational in the recollection of words; these words were not stimulated by the sequence but they emerged as a result of being part of the schema which contains the stimulant words tea, spill and break. It is interesting to observe that no strong collocations emerged with the word window. The words curtain, scene, glass and dust seem to be collocations but the collocative quality of "window curtain" or other pairs, is rather weak compared to that of the pair "tea break". This may be because the word window is not used before certain words oftener than other words and thus it does not stimulate a relational priority as a result of priming for the emergence of certain words, except for the words curtain and view in our data set.

It is observed that failure is higher with some certain items on the list we administered in Task 1 and Task 2. This might imply that while some of the words present fostering clues for the learner, others lack such clues. Thus they are not recollected by the majority of the participants. However this proposition requires further research.

In the early part of the twentieth century, conceptualizations or theories of how languages were learned (both first and second) relied heavily on the input provided to the learner. This was particularly the case within the behaviorist period of language study, a research tradition that can reasonably be seen as falling outside of the "modern era" of language acquisition research. Within the behaviorist orthodoxy, language acquisition was seen to rely entirely on the input that a child received because, within that framework, a child was seen to learn by imitation (Gass, 2003: 228).

Although Gass (2003: 228) states that behaviorist understanding is outdated, it is often observed in the classrooms that teachers teach, at least some aspects of foreign language, viz vocabulary, in the way behaviorism conceives of language acquisition. Word listing is one of these classroom practices. This study presents some evidence that listing and asking students to memorize those words cause problems in the retrieval processes of retained words which may cause problems in the productive stage of foreign language learning (see Hartley, Little, Speer and Jonides, 2011).

\section{References}

Atkinson, R. C., \& Raugh, M. R. (1975). An application of the mnemonic keyword method to the acquisition of a Russian vocabulary. Journal of experimental psychology: Human learning and memory, 4(2), 126-133. http://dx.doi.org/10.1037/0278-7393.1.2.126

Ausubel, D., \& Fitzgerald, D. (1961). The role of discriminability in meaningful verbal learning and retention. Journal of educational psychology, 52(5), 266-74. http://dx.doi.org/10.1037/h0045701 
Baleghizadeh, S., \& Ashoori, A. (2010). The effect of keyword and word list methods on immediate vocabulary retention of EFL learners. Pakistan journal of social sciences, 30(2), 251-261. Retrieved from http://www.bzu.edu.pk/PJSS/Vol30No22010/Final_PJSS-30-2-06.pdf

Brown, H. D. (1994). Principles of language learning and teaching (3rd edition). Englewood Cliffs, NJ: Prentice Hall Regents.

Budvig, N. (2002). A developmental-functionalist approach to mental state talk. In Eric Amsel, \& James P. Byernes (Eds.), Language, literacy, and cognitive development: the development and consequences of symbolic communication. Mahwah: Lawrence Erlbaum Associates. ISBN 0-8058-3494-X.

Busato, V. V., Prins, F. J., Elshout, J. J., \& Hamaker, C. (1999). The relation between learning styles; the big five personality traits and achievement motivation in higher education. Personality and individual differences, 26, 129-140. http://dx.doi.org/10.1016/S0191-8869(98)00112-3

Byers, J. L. (1967). Verbal and concept learning. Review of educational research, 37(5), 494-513. http://dx.doi.org/10.2307/1169509

Chastain, K. (1988). Developing second language skills: Theory and practice (3rd edition). San Diego, CA: Harcourt Brace Jovanovich.

Craik, F. I. M., \& Tulving, E. (1975). Depth of processing and the retention of words in episodic memory. Journal of experimental psychology: General, 104(3), 268-294. http://dx.doi.org/10.1037/0096-3445.104.3.268

Davies, G., \& Milne, A. (1982). Recognizing faces in and out of context. Current psychology, 2(4), 235-246. http://dx.doi.org/10.1007/BF02684516

Dijkstra, K., Kaschak, M. F., \& Zwaan, R. A. (2007). Body posture facilitates retrieval of autobiographical memories. Cognition, 102, 139-149. http://dx.doi.org/10.1016/j.cognition.2005.12.009

Felder, R. M., \& Brent, R. (2005). Understanding student differences. Journal of engineering education, 94(1), 57-72. Retrieved from http://www.jee.org/2005/january/243.pdf

Fernandez, E. M., \& Cairns, H. S. (2010). Fundamentals of psycholinguistics. West Sussex. Wiley-Blackwell.

Gass, S. M. (2003). Input and interaction. In Catherine Doughty and Michael H. Long (Eds.), The handbook of second language acquisition (pp. 224-255). Oxford: Blackwell.

Gagnon, S., Bedard, M. J., \& Turcotte, J. (2005). The effect of old age on supra-span learning of visuo-spatial sequences under incidental and intentional encoding instructions. Brain and cognition, 59, 225-235. http://dx.doi.org/10.1037/0882-7974.20.2.251

Habib, R., McIntosh, A. R., \& Tulving, E. (2000). Individual differences in the functional neuroanatomy of verbal discrimination learning revealed by positron emission tomography. Acta psychological, 105, 141-157. http://dx.doi.org/10.1016/S0001-6918(00)00058-5

Hartley, A. A., Little, D. M., Speer, N. K., \& Jonides, J. (2011). Input, retention, and output factors affecting adult age differences in visuospatial short-term memory. J Gerontol B Psychol Sci Soc Sci, 66B, 435-443. http://dx.doi.org/10.1093/geronb/gbr020

Kerzel, D. (2003). Attention maintains mental extrapolation of target position: Irrelevant distractors eliminate forward displacement after implied motion. Cognition, 88, 109-131. http://dx.doi.org/10.1016/S0010-0277(03)00018-0

Maki, W. S. (2007). Judgments of associative memory. Cognitive psychology, 54, 319-353. http://dx.doi.org/10.1016/j.cogpsych.2006.08.002

Matthews, G. (2009). Personality and performance: cognitive processes and models. In Philip, J. Corr, \& Gerald Matthews (Eds.), The Cambridge handbook of personality and psychology (pp. 400-426). Cambridge: CUP.

Mc Donald F. J. (1964). Meaningful learning and retention: task and method variables. Review of educational research, 34(5), 530-544. http://www.jstor.org/stable/1169664

Niu, R., \& Andrew, S. (2012). Commonalities and discrepancies in L2 teachers' beliefs and practices about vocabulary. Pedagogy: A Small Culture Perspective. TESOL Journal, 6, 134-154. Retrieved from http://www.tesol-journal.com/A9_V6.pdf

Özcan, M. (2012a). Developmental differences in the naming of contextually non-categorical objects. Journal of psycholinguistic research, 41(1), 51-69. http://dx.doi.org/10.1007/s10936-011-9176-0 
Özcan, M. (2012b). Novelist Calls Out Poemist: A psycholinguistic and contrastive analysis of the errors in Turkish EFL learners' interlanguage. International journal of social and human sciences, 6, 559-570. Retrieved from http://www.waset.org/journals/ijshs/v6/v6-94.pdf

Phillips, L. (1988). Young readers' inference strategies in reading comprehension. Cognition and instruction, 5(5), 193-222. Retrieved from http://www.jstor.org/stable/3233579

Postma, A., Jager, G., Kessels, R. P. C., Koppeschaar, H. P. F., \& Van Honk, J. (2004). Sex differences for selective forms of spatial memory. Brain and cognition, 54, 24-34. http://dx.doi.org/10.1016/S0278-2626(03)00238-0

Prince, A., \& Smolensky, P. (1993). Optimality theory. Constraint interaction in generative grammar. Book manuscript, Rutgers University and University of Colorado at Boulder.

Prince, P. (1996). Second language vocabulary learning: the role of context versus translations as a function of proficiency. The modern language journal, 80(4), 478-493. Retrieved from http://www.jstor.org/stable/329728

Richardson, J., \& Hersh, L. R. (1974). Response selection in paired associate learning. Memory and cognition, 2(2), 391-394. http://dx.doi.org/10.3758/BF03209015

Ringbom, H. (1987). The role of first language in foreign language learning. Clevedon: Multilingual matters.

Sankó, G. (2006). The effects of hypertextual input modification on L2 vocabulary acquisition and retention. In M. Nikolov, \& J. Horváth (Eds.), UPRT 2006: Empirical studies in English applied linguistics (pp. 157-178). Pécs: Lingua Franca Csoport.

Shulman, A. I. (1974). Memory for words recently classified. Memory and cognition, 2(1A), 47-52. http://dx.doi.org/10.3758/BF03197491

Smith, S. M. (1979). Remembering in and out of context. Journal of experimental psychology: Human learning and memory, 5(5), 460-471. http://dx.doi.org/10.1037/0278-7393.5.5.460

Tessmer, M., \& Richey, R. C. (1997). The role of context in learning and instructional design. Educational technology research and development, 45(2), 85-115. http://dx.doi.org/10.1007/BF02299526

Thomson, D. M., \& Tulving, E. (1970). Associative encoding and retrieval processes in episodic memory. Psychological Review, 80, 352-373.

Wyra, M., Lawson, M. J., \& Hungi, N. (2007). The mnemonic keyword method: The effects of bidirectional retrieval training and of ability to image on foreign language vocabulary recall. Learning and instruction, 17(3), 360-371. http://dx.doi.org/10.1016/j.learninstruc.2007.02.008 